\title{
OPTIMIZATION OF THE NATIONAL IGNITION FACILITY PRIMARY SHIELD DESIGN
}

\author{
C. E. Annese, J. Latkowskl, J.D. Lee, P. Soran, and M.L. Tobln \\ Lawrence Livermore National Laboratory
}
E.F. Watkins, E. Greenspan, and W.F. Miller University of Callfornia - Berkeley

This paper was prepared for submittal to:

15th IEEENPSS Symposium on

Fusion Engineering

Cape Cod, MA

October 11-15, 1993

October, 1993

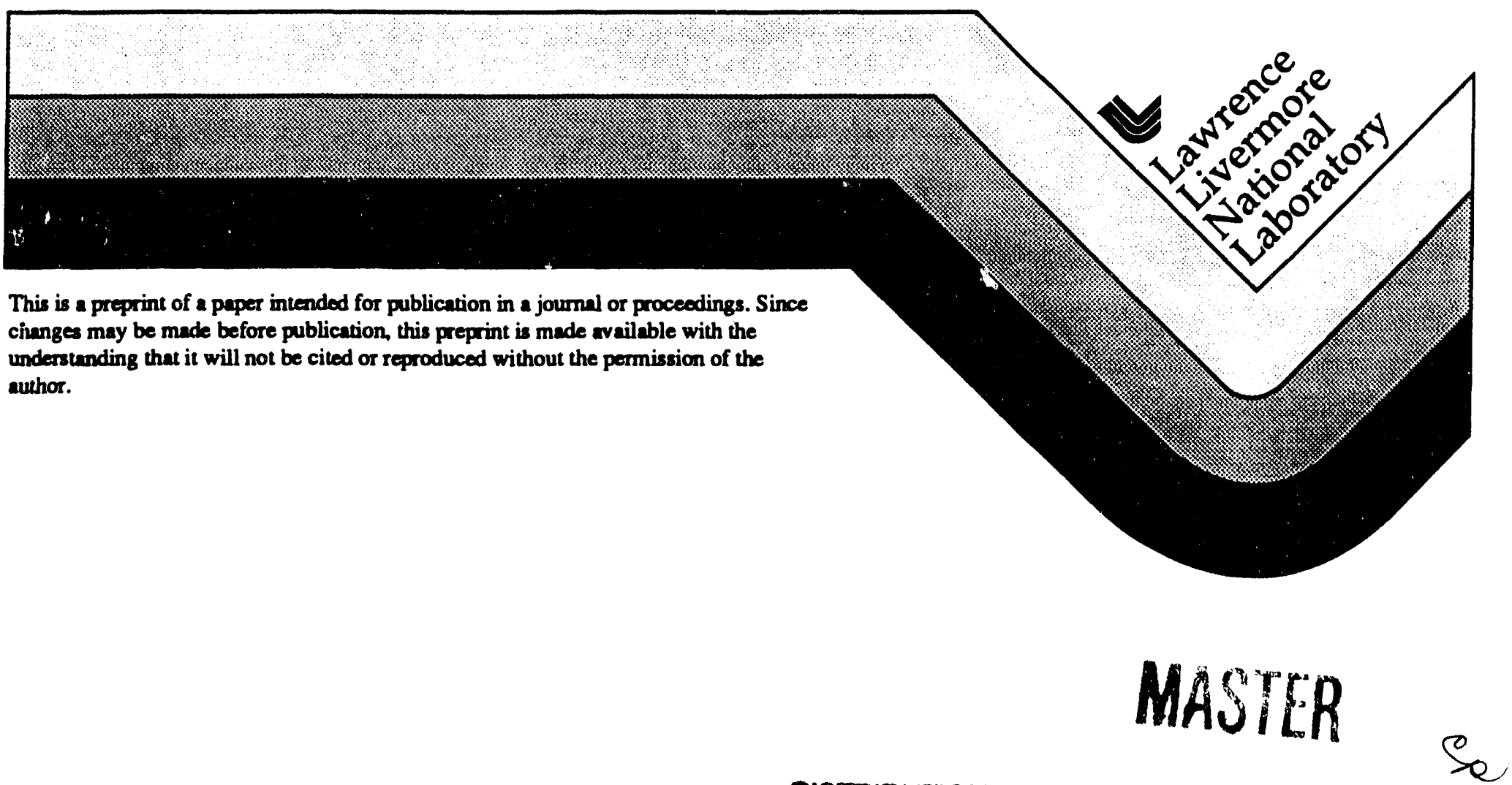




\section{DISCLAIMER}

This document was prepared as an account of work sponsored by an agency of the United States Government. Neither the United States $($. Whent nor the University of California nor any of their employees, makes any warranty, expressed or implied, or assumes any legal liability or responsibility for the accuracy, completeness, or usefulness of any information, apparatus, product, or process disclosed, or represents that its use would not infringe privately owned rights. Reference herein to any specific

commencial products, process, or service by trade name, trademark, manufacturer, or otherwise, does not necessarily constitute or imply its endorsement, recommendation, or favoring by the United States Government or the University of California. The views and opinions of authors expressed herein do not necessarily state or reflect those of the United States Government or the University of California, and shall not be used for advertising or product endorsement purposes. 


\section{Optimization of the National Ignition Facility Primary Shield Design*}

\author{
C.E. Annese, E.F. Watkins, \\ E. Greenspan, and W.F. Miller \\ Department of Nuclear Engineering \\ University of California \\ Berkeley, CA 94720
}

\section{ABSTRACT}

Minimum cost design concepts of the primary shield for the National Ignition laser fusion experimental Facility (NIF) are searched with the help of the optimization code SWAN. The computational method developed for this search involves incorporating the time dependence of the delayed photon field within effective delayed photon production cross sections. This method enables one to address the time-dependent problem using relatively simp'e, time-independent transport calculations, thus significantly simplifying the design process. A novel approach was used for the identification of the optimal combination of constituents that will minimize the shield cost; it involves the generation, with SWAN, of effectiveness functions for replacing materials on an equal cost basis. The minimum cost shield design concept was found to consist of a mixture of polyethylene and low cost, low activation materials such as SiC, with boron added near the shield boundaries.

\section{INTRODUCTION}

Preliminary studies $[1,2]$ examined a number of design concepts for the bulk shield of the target chamber of the National Ignition laser fusion Facility (NIF; previously referred to as the Nova Upgrade, a candidate for the NIF). The present paper summarizes a second round of conceptual nuclear design of this shield. It differs from the first round in four aspects: (1) The laser shot scenario, (2) The aluminum chamber design, (3) The calculational method used, and (4) The wider range of shield designs examined.

The original shielding concept for the NIF target chamber consisted of a few centimeters thick aluminum chamber interfacing the cavity, followed by a shield. This, so called, "outer shield" was to have a dual function: (a) Attenuate the photons resulting from the decay of the activation of the aluminum chamber, and (b) Slow down and attenuate the flux of neutrons leaking out from the chamber shield to reduce the activation of the space frame and concrete to an acceptable level. The present study addresses this outer shield approach as well as an inner shield approach. The latter features the shielding material internal to the main Al chamber to minimize the structural material activation. In the following we shall only refer to the outer shield approach. An account of the inner shield approach can be found in Ref. 3.

* This work was performed under the auspices of the U.S. DOE by LLNL under contract no. W-7405-Eng-48.

\author{
J. Latkowski, J. D. Lee, \\ P. Soran and M. L. Tobin \\ Lawrence Livermore National Laboratory \\ Livermore, CA 94550
}

A comprehensive description of the efficient methodology used for this study and of the results obtained will be available in Ref. 3. In the following we shall briefly summarize the methodology, amplifying on aspects not covered in Ref. 3, and shall provide a complete accuunt of the cost optimization studies.

\section{OPTIMIZATION PROBLEM DEFINITION}

A cycle of twenty nine laser shots of different yields is being contemplated for the NIF. Different waiting periods are contemplated between shots of different yields. Access to. the experimental hall is allowed for a duration of six hours preceeding the next shot. The twenty nine shot cycle will allow approximately 145 shots per year. The planned life of the NIF is ten years. The set of constraints imposed on the design of the NIF is presented in detail in Ref. 1. The present study was to consider a single constraint: the maximum accumulated yearly dose one can accumulate will not exceed $200 \mathrm{mR}$. This is without accounting for the streaming of radiation through the beam lines.

Physically, the NIF shield design problem is timedependent. The maximum accumulated dose will be obtained if one would be exposed to the highest dose rate in the experimental hall throughout the six hours access time following each of the laser shots during the linth and last operating year. This maximum Dose which can be Accumulated during the Last Year of operation will be referred to as the DALY.

\section{COMPUTATENAL METPOU}

The conventional appe wh the calnulation of the DALY involves the follcwin s, $r$ : $\langle a\rangle, \therefore$ ive a timeindependent transport code in sibs live istegrated (per

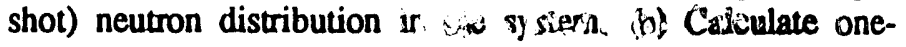
group effective activation criss is dions for zeactions of

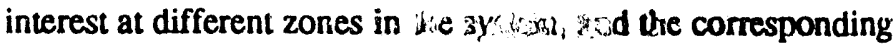
one-group fluxes. ( $c)$ Use $t$ abos sne-fromet jata to calculate

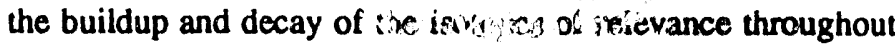
the 10 years of operation of is ty alculations are to account for each of the lasers 5, trughout that period. They are to be repeated for each 20 sis the system. (d) Using the source of delayed photons during the access time, calculate the transport of these photons in the system. Use this photon distribution to calculate the dose rate in desired locations. 


\section{A. Single-Step Time-Independent Calculations}

A different calculational approach was used in the present work. It involves the transformation of the timedependent problem to a completely time-independent problem which can be solved in a single run and which can accurately take into account the contribution of as many reactions as desired. This approach involves the replacement of the prompt photon production cross sections by effective delayed photon production cross-sections. Such an approach was first conceived by P. Levine and implemented by B.A. Engholm [4] for a very different application. A similar approach was later used by S. L. Liew and L.P. Ku $[5,6]$, who also worked out a detailed theoretical formulation. However, whereas the methods of Levin-Engholm and Liew-Ku can handle one delayed photon effect at a time, the calculational approach we conceived can simultaneousely account for any number of delayed photon effects as well as of prompt photon effects in a single computer run. Details about our method can be found in Refs. 3 and 7.

The modified coupled neutron-photon libraries generated enable calculation of all the performance characteristics of relevance (in general, both prompt and delayed) in one run of a single time-independent transport code. Moreover, the modified library enables one to apply the one-dimensional code SWAN [8] to search for an optimal shield design for NIF. SWAN uses ANISN for solving the coupled neutron-photon transport equation, as well as the adjoint equation for the DALY. Using the above solutions, SWAN calculates the "material effectiveness functions". These effectiveness functions express the effect a change in composition anywhere in the shield will have on the DALY. They provide a highly valuable guidance to the search for the optimal shield composition, both to the designer and to SWAN.

\section{B. Differential Contribution to the DALY}

By multiplying the source of delayed photons pertaining to group $g$ which comes from activation product $P$ in interval I with the adjoint function of group $g$ at $I$, and summing over all the energy groups having delayed photons from the decay of $P$, one gets the total contribution of $P$ at $I$ to the DALY. Figs. 1 and 2 illustrate the kind of differential information obtainable this way.

The leftmost peak in Fig. 1 represents the activation of the target chamber, whereas the right peak represents activation of the Al structure outside of the target chamber (the so called "space frame"). It is seen that the activation of the space frame makes a dominant contribution to the DALY, which is measured between the space frame and the shield. Fig. 2 shows the contribution of radiative capture in the sodium in the concrete walls of the experimental hall. This contribution is small.

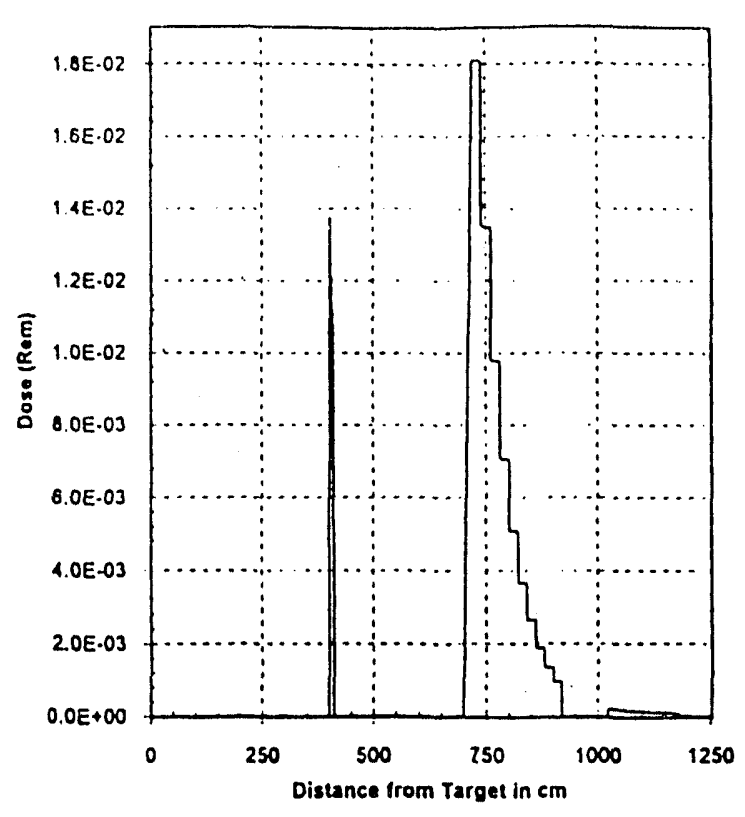

Fig. $1 \mathrm{Al}^{27}(\mathrm{n}, \alpha) \mathrm{Na}^{24}$ contribution to dose.

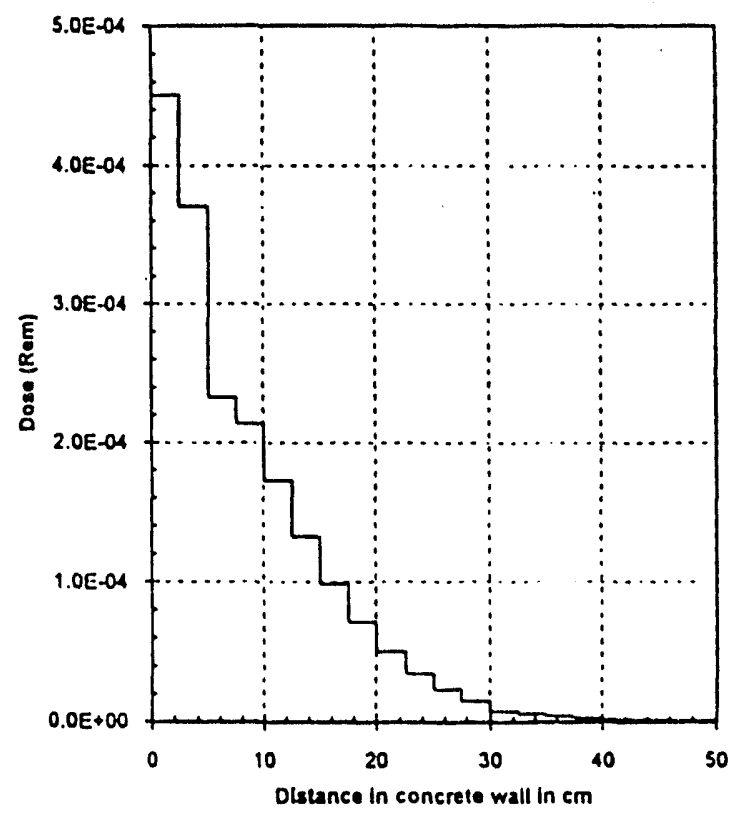

Fig. $2 \mathrm{Na}^{23}(\mathrm{n}, \gamma) \mathrm{Na}^{24}$ contribution to dose.

\section{Equal Cost Replacement Effectiveness Functions}

The effectiveness functions originally generated and used by SWAN are on per unit volume basis. For the purpose of this study, SWAN was extended to calculate Replacement Effectiveness Functions (REFs) on per equal material cost basis. We shall refer to them as Equal Cost REF (ECREF). The definition of ECREFs can be found in Refs. 3 and 9. Illustartions of ECREFs are given in the following section.

\section{SEARCH FOR OPTIMAL SHIELD DESIGN}

The materials specified for the reference NIF are Al- 
5083, lead-borated-polyethylene ( $R / X$ material \# 202 [10]), concrete and rebar. Based on earlier studies $[1,2]$, it was decided to consider polyethylene (Poly) as the base shielding material. The questions to be addressed are: (a) What are the most promising additives to the Poly. (b) Where to !ocate these additives, and (c) How thick need be the resulting shield. Lead and boron were presumed to be desirable additives to the Poly. In addition, the following nonconventional additives were selected for consideration: tungsten, titanium hydride, silicon dioxide, silicone carbide, calcium carbonate, calcium oxide and magnesium oxide. The incentive for considering tungsten and titanium hydride is based on their outstanding attenuation ability [11]. The other materials are characterized by higher than Poly density, low activation and low cost. They are to be in the form of a powder bonded by Poly, and are referred to as "polynated" materials.

Polynated $\mathrm{SiC}$, and like materials considered in this work, are members of a new family of shielding materials being developed by Reactor Experiments, Inc. [12]. They appear promising for the NIF primary shield application; compared with pure Poly they offer not only a significantly betaer photon attenuation (due to their higher average $\mathrm{Z}$ ), but also better attenuation of the $14 \mathrm{MeV}$ neutrons! Thus, the DALY behind a $50 \mathrm{~cm}$ thick shield for the NIF made of $50 \mathrm{v} / \mathrm{o}$ powder of $\mathrm{SiO}_{2}, \mathrm{SiC}, \mathrm{CaO}$ or $\mathrm{MgO}$ bonded by $50 \mathrm{v} / \mathrm{o}$ Poly is calculated to be, respectively, $0.30,0.13,0.12$ or 0.26 relative to the DALY behind a $50 \mathrm{~cm}$ thick shield made of pure Poly.

Fig. 3 shows the Equal Volume REFs, while Fig. 4 shows the Equal Cost REFs calculated with SWAN for a number of potential shield constituents reititive to pure Poly $(\mathrm{R} / \mathrm{X}$ material \# 213 [10]) in a $42 \mathrm{~cm}$ thick homogeneous shield made of $85.46 \mathrm{v} / \mathrm{o}$ Poly and $14.54 \mathrm{v} / \mathrm{o}$ lead. This shield was found [3] to be more cost effective than the reference shield made of $R / X$ \# 202 (having, essentially, the same constituents). Shown in Figs. 3 and 4 are only negative values of the REFs; a positive REF implies that the replacement of Poly by an equal volume or cost of the corresponding material will result in an increase in the DALY. In calculating the ECREF values we assumed [12] that relative to the cost of pure Poly, the cost of SiC, borated-Poly (R/X material \# 201), $\mathrm{Pb}, \mathrm{B}, \mathrm{C}, \mathrm{TiH}_{2}$ and $\mathrm{W}$ is, respectively, 1.0, 1.1, 12.0, 39.5, 166 , and 324.

From the EVREF data of Fig. 3 it is observed that, on per equal volume basis, (a) Tungsten is the most effective additive to Poly. Adding' $W$ at the outer side of the shield is nearly one order of magnitude more effective than adding it at the inner part of the shield. (b) Lead is about $2 / 3$ as effective as W. (c) Replacement of some of the Poly with $\mathrm{B}_{4} \mathrm{C}$ is expected to be beneficial, especially near the shield surfaces. (d) $\mathrm{SiC}, \mathrm{R} / \mathrm{X}$ material \#201, and $\mathrm{TiH}_{2}$ can also reduce the DALY, but not as effectively as the other materials.

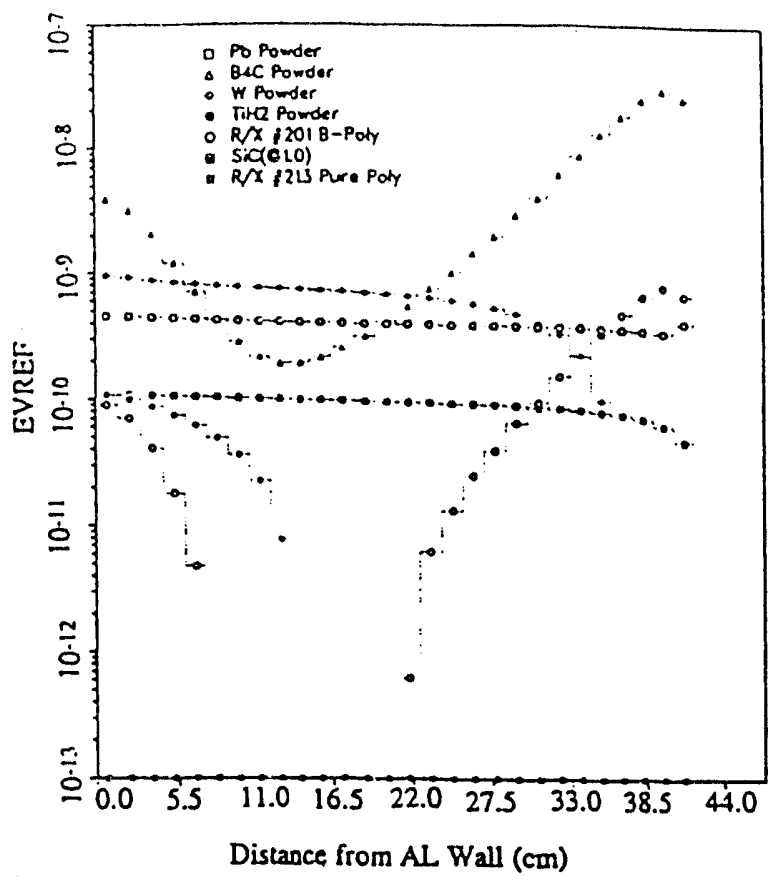

Fig. 3 EVREFs relative to Poly in a uniform homogeneous shield made of $85.46 \mathrm{v} / \mathrm{o}$ Poly and $14.54 \mathrm{v} / \mathrm{o} \mathrm{Pb}$.

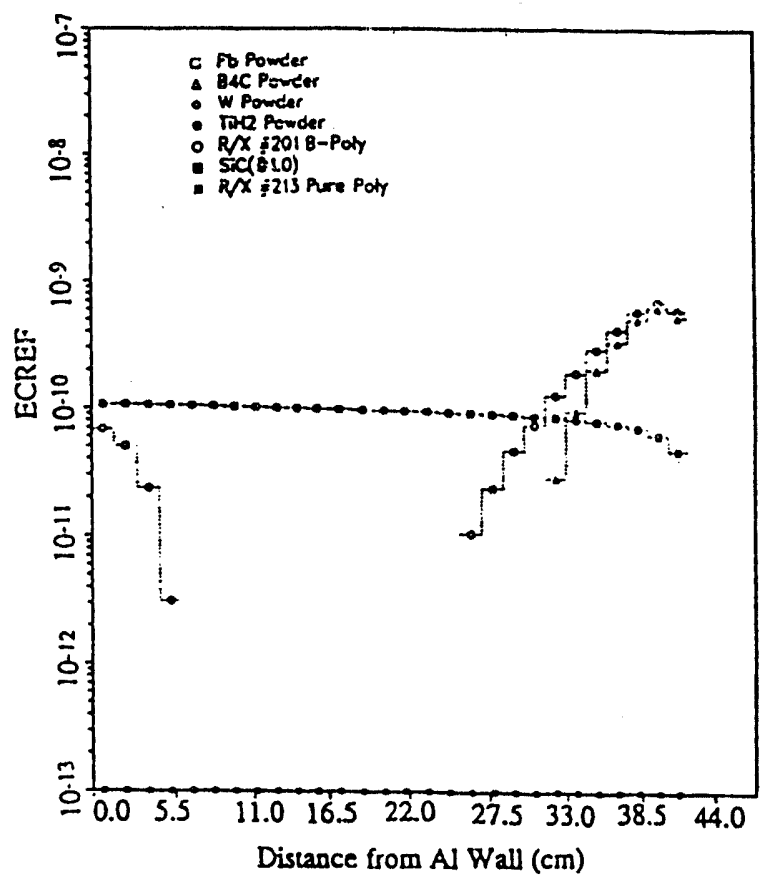

Fig. 4 ECREFs relative to Poly in a uniform homogeneous shield made of $85.46 \mathrm{v} / \mathrm{o}$ Poly and $14.54 \mathrm{v} / \mathrm{o} \mathrm{Pb}$.

A very different story is being told by the ECREF data of Fig. 4. Of the six candidate materials considered, only three can provide cost-effective replacements for Poly. They are, in descending order of overall cost reduction potential, $\mathrm{SiC}, \mathrm{B}$-Poly and $\mathrm{B}_{4} \mathrm{C}$. Notice that the $\mathrm{Pb}$ is to be removed.

Fig. 5 shows the cost of polynated $\mathrm{SiC}$ shields as a function of the $\mathrm{SiC}$ volume ratio, relative to the cost of a shield made of pure Poly. The two constituents are assumed to be 
homogeneousely distributed throughout the shield. Of the two pairs of plots, one pertains to pure Poly while the other to borated Poly. A couple of cost figures are assigned to the $\mathrm{SiC}$; they are likely to bracket the real cost for large quantities of this material. The maximum practical loading of $\mathrm{SiC}$ (and other types of) powder into Poly is approximately 50v/o [12]. In this range Fig. 5 shows that pure Poly is more cost effective than borated Poly.

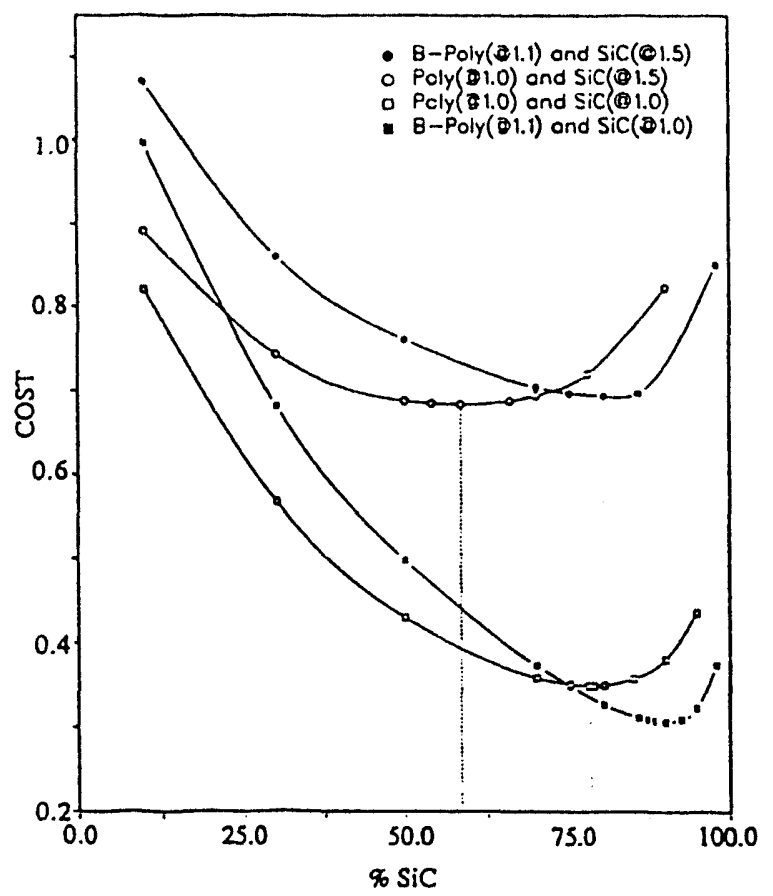

Fig. 5 Cost of NIF target chamber primary shield made of $\mathrm{SiC}$ homogeneously mixed with pure or borated polyethylene, relative to cost of shield made of pure Poly.

If the cost of $\mathrm{SiC}$ is 1.5 times the cost of pure Poly, its optimal loading is nearly $58 \mathrm{v} / \mathrm{o}$. At this concentration the ECREF averaged over the shield volume is found to be zero. However, examination of the ECREFs calculated for this uniform shield indicates that the SiC ECREF actually varies across the shield. If the $\mathrm{SiC}$ could be segregated in the inner part of the shield, the shielding performance would have been improved (or the shield cost reduced). Applying SWAN to search for the optimal $\mathrm{SiC}$ distribution in pure Poly indeed concentrated the $\mathrm{SiC}$ in the inner side of the shield. However. as the price of solid $\mathrm{SiC}$ is high, such an heterogeneous arrangement is not cost effective. The ECREFs also suggest that replacement of some of the Poly by borated Poly (or $\mathrm{B}_{4} \mathrm{C}$ ) will be cost effective. A litule lead near the outer face of the shield is also expected to reduce the shield cost. However, the overall attainable cost reduction is not expected to be large, and we did not apply SWAN to identify the optimal combination of SiC, Poly, boron and lead.

$$
\text { SUMMARY }
$$

chamber was found to consist of a powder of $\mathrm{SiC}$ bonded by polyethylene. Such a shield is estimated to cost only approximately $25 \%$ of the cost of the reference shield, which was to use the commercially available lead-boratedpolyethylene material ( $\mathrm{R} / \mathrm{X} \# 2$ 202). Polynated $\mathrm{CaO}$ (or $\mathrm{CaCO}_{3}$ ) is another attractive candidate for the NIF target chamber shield. The conception of this new shield design is attributed to the unique information and insight provided by the optimization code SWAN. The application of the timeindependent code SWAN to the time-dependent problem was made possible by replacing, in the coupled neutron-photon cross-section library, the prompt photon production crosssections by effective delayed photon production cross-sections. The SWAN output also enables to efficiently get the spacedependent contribution of each activation product to the DALY, thus providing additional information and insight.

\section{REFERENCES}

[1] W.R. Meier, M.T. Tobin and M.S. Singh, "Radiological analysis for Nova Upgrade," Fusion Technology, 19, 1362 (1991).

[2] M.T. Tobin, J.R. Smith, D. Campbell and D.K. Wong, "Target area for Nova Upgrade: containing ignition and beyond," Proc. IEEE/NPSS 14th Symp. on Fusion Engineering, San Diego, CA, Sept. 30-Oct. 4, 1991.

[3] E. Greenspan, C. E. Annese, J. Latkowski, J. D. Lee, W. F. Miller, P. Soran, M. Tobin, E. F. Watkins, "Conceptual design of the National Ignition Facility primary shield," Fusion Technology, unpublished

[4] B.A. Engholm, "Shutdown dose rate studies for TFCX," Fusion Technology, 8995 (1985).

[5] S.L. Liew and L.P. Ku, "Monte Carlo calculation of delayed gamma dose rate in complex geometry using the concept of effective delayed gamma production cross section," Nucl. Sci. \& Eng., 107, 114 (1991).

[6] S.L. Liew and L.P. Ku, "Shielding design optimization for the compact ignition tokamak test cell building," Fusion Technology, 20, 164 (1991).

[7] C. E. Annese, E. Greenspan ang W.F. Miller, "Simultaneous calculation of prompt and delayed photon effects," ANS Transactions, 68, 392 (1993).

[8] E. Greenspan, W.G. Price and H. Fishman, "SWAN: A code for the analysis and optimization of fusion reactor nucleonic characteristics," Princeton Plasma Physics Lab. Report MATT-1008, (1973).

[9] E. F. Watkins, C. E. Annese, E. Greenspan, "Shield cost minimization using SWAN," ANS Transactions, 68, 393 (1993).

[10] Reactor Experiments, Inc. Catalog, 1275 Hammerwood Av., Sunnyvale, CA 94089-2231.

[11] E. Greenspan, "High effectiveness shielding materials and optimal shield design," J. Testing and Evaluation, 20, 71 (1992).

D. White, Reactor Experiments, Inc., Personal Communication, 1992. 

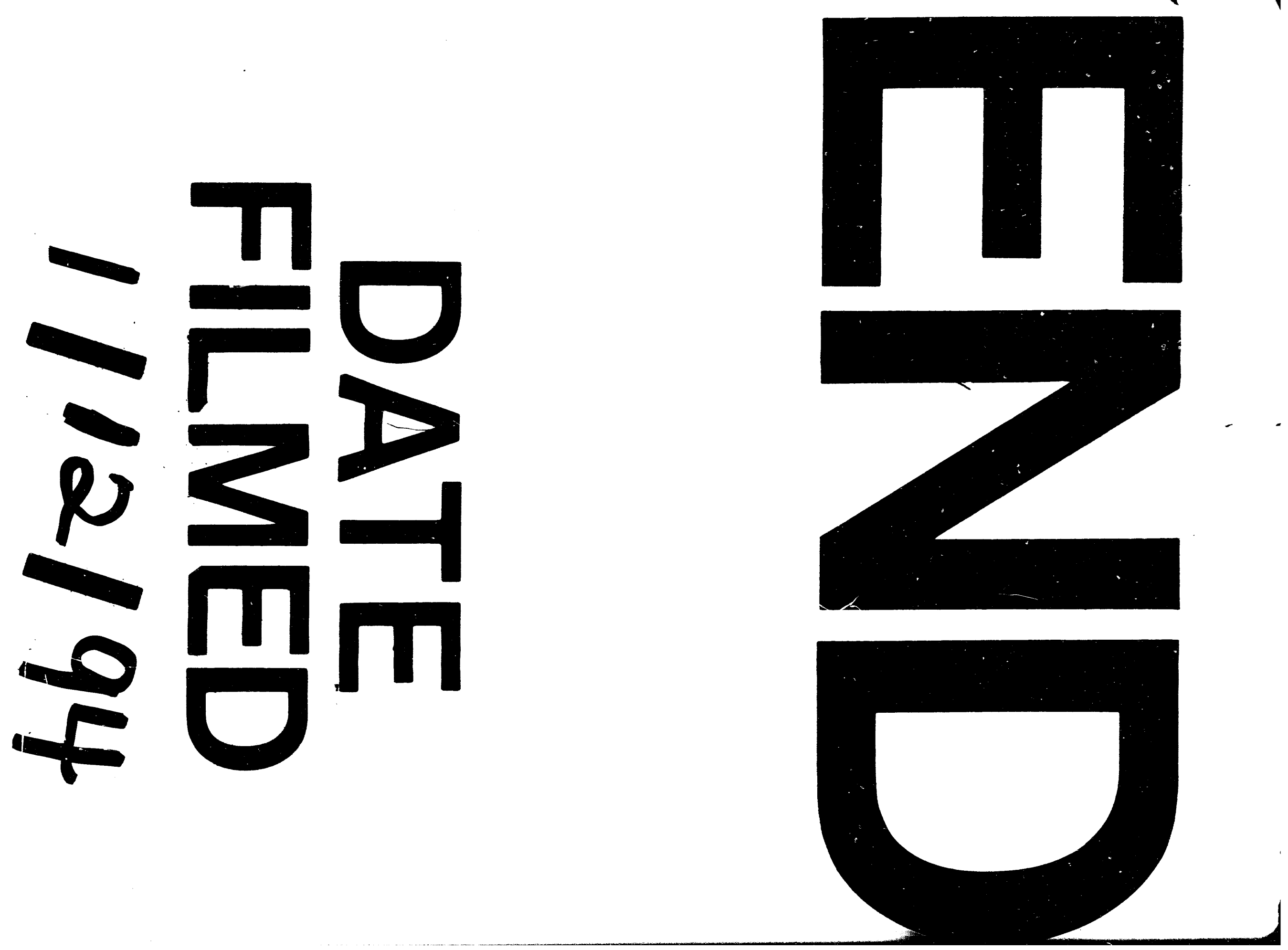
